Article

\title{
Investigation into the Effect of Cutting Conditions in Turning on the Surface Properties of Filament Winding GFRP Pipe Rings
}

\author{
Gabriel Mansour ${ }^{1}$, Panagiotis Kyratsis ${ }^{2}\left(\mathbb{D}\right.$, Apostolos Korlos ${ }^{3} \mathbb{D}$ and Dimitrios Tzetzis ${ }^{4, *}(\mathbb{D})$ \\ 1 Department of Mechanical Engineering, Aristotle University of Thessaloniki, 54124 Thessaloniki, Greece; \\ mansour@auth.gr \\ 2 Department of Product and Systems Design Engineering, University of Western Macedonia, \\ 50100 Kila Kozani, Greece; pkyratsis@uowm.gr \\ 3 Department of Production Engineering and Management, International Hellenic University, \\ 57400 Sindos, Greece; apkorlos@ihu.gr \\ 4 School of Science and Technology, International Hellenic University, 57001 Thermi, Greece \\ * Correspondence: d.tzetzis@ihu.edu.gr
}

Citation: Mansour, G.; Kyratsis, P.; Korlos, A.; Tzetzis, D. Investigation into the Effect of Cutting Conditions in Turning on the Surface Properties of Filament Winding GFRP Pipe

Rings. Machines 2021, 9, 16.

https://doi.org/10.3390/

machines 9010016

Received: 11 December 2020

Accepted: 12 January 2021

Published: 15 January 2021

Publisher's Note: MDPI stays neutral with regard to jurisdictional claims in published maps and institutional affiliations.

Copyright: (c) 2021 by the authors. Licensee MDPI, Basel, Switzerland. This article is an open access article distributed under the terms and conditions of the Creative Commons Attribution (CC BY) license (https:// creativecommons.org/licenses/by/ $4.0 /)$.

\begin{abstract}
There are numerous engineering applications where Glass Fiber Reinforced Polymer (GFRP) composite tubes are utilized, such as desalination plants, power transmission systems, and paper mill, as well as marine, industries. Some type of machining is required for those various applications either for joining or fitting procedures. Machining of GFRP has certain difficulties that may damage the tube itself because of fiber delamination and pull out, as well as matrix deboning. Additionally, short machining tool life may be encountered while the formation of powder like chips maybe relatively hazardous. The present paper investigates the effect of process parameters for surface roughness of glass fiber-reinforced polymer composite pipes manufactured using the filament winding process. Experiments were conducted based on the high-speed turning Computer Numerical Control (CNC) machine using Poly-Crystalline Diamond (PCD) tool. The process parameters considered were cutting speed, feed, and depth of cut. Mathematical models for the surface roughness were developed based on the experimental results, and Analysis of Variance (ANOVA) has been performed with a confidence level of $95 \%$ for validation of the models.
\end{abstract}

Keywords: turning; GFRP pipes; surface properties; filament winding

\section{Introduction}

Today, there is an increasing use of composite laminates in engineering applications, due to their high strength-to-weight ratio, as well as excellent corrosion and fatigue resistance. Continuous and extensive research and development in composite material science and technology led to the growing increase in the usage of composite materials from primary applications, such as the interiors of automobiles, to very advanced applications in automotive, aerospace, marine, and off-shore industries. The manufacturing flexibility of composites having customized mechanical properties for specific applications has been one of their greater advantages and also one of the more perplexing challenges to adopting them as alternative to conventional materials [1-3].

Today, there is a good knowledge on manufacturing Glass Fiber Reinforced Polymer (GFRP) products using the filament winding technique [4]. Composite tubes, in particular, are widely used for a range of industrial applications [5]. They outperform traditional pipe materials in applications requiring low weight, corrosion resistance, and high strength. Composite tubes are usually manufactured by the filament winding process where controlled amount of resin and oriented composite fibers are wound around a rotating mandrel and cured to produce the required composite part [6]. The use of machining is increasing as the field of application of composite pipes is increasing [7]. However, it is often difficult 
to machine the GFRP composite tubes since such procedure brings many undesirable results, such as rapid tool wear, a defective surface layer with cracks or delamination, a rough surface finish, etc. To avoid such problems, it is necessary to select the appropriate process parameters and thereby to achieve the highest performance for desired dimensional accuracy.

Many researchers had studied the effect of input machining parameters on cutting quality [8,9]. Dehghan et al. [10] investigated the effect of drilling parameters, such as spindle speed, feed rate, diameter and drill geometry on the thrust force, and the delamination factor for the composite pipes, produced by the filament winding process. Korlos et al. [11] compared the delamination effects in drilling and Electrical Discharge Machining (EDM) procedures in CFRP composites, while Prasad et al. [12] analyzed the surface roughness behavior from different hole cutting conditions on GFRP composites using abrasive water jet machining. Additionally, El-Ghaoui et al. [13] investigated the effects of a graphene filled matrix on GFRP machinability.

In particular, the machining of FRP is different from that of metal working in many respects because the metal behavior is not only inhomogeneous but also dependent on fiber and matrix properties, fiber orientation, and the type of fibers. In machining, most of the composite materials produce discontinuous, powdery chips. The powdery chips pose health hazard to the operator. Collection and disposal of the chips is also a problem. Proper safety equipment must be used while working with these composite materials. The tool wear must be kept at a minimum when machining composite materials. During the machining operation, the tool continuously machines matrix and fiber materials sometimes at different orientations; thereby, their response to machining can vary greatly. Both thermal and mechanical stresses are induced in the cutting zone. Due to the variations in properties of matrix and fiber, the cutting nose may be subjected to localized dynamic loading. Such load may cause tool failure due to possible low cycle fatigue apart from the usual types of wear. The surface quality is related with the features that are generated on the machined surface. For optimized surface finish, it is necessary to understand the mechanisms of the material removal and the kinetics of machining processes that affect the performance of the cutting tool. It is understood that the cutting mechanism of the composite materials is due to a combination of plastic deformation of the matrix, shearing, and bending rupture of the fibers. The severity of such mechanisms depends on the toughness of the reinforcing fibers/particles their flexibility and orientation. As in metals, the surface roughness can be assessed by the different surface roughness parameters, such as arithmetic average height $(\mathrm{Ra})$, the average maximum peak to valley of five consecutive sampling lengths within the measuring length $(\mathrm{Rz})$, root mean square roughness $(\mathrm{Rq})$, maximum height of peaks $(\mathrm{Rp})$, maximum height of the profile (Rt), or mean of the third point height (R3z). Even though many surface roughness parameters are used, the average surface roughness (Ra), which is most used in industries. On an FRP machined surface, the result of the surface roughness test depends mainly on the direction of fibers, which changes from layer to layer. In addition, the method that is used to measure the surface features is very important since contact and non-contact methods might give slightly different values.

Davim et al. [14] presented an optimization study of surface roughness in turning FRPs tubes manufactured by filament winding and hand lay-up, using polycrystalline diamond cutting tools. In Naveen et al.'s [15] work, the machining characteristics of GFRP pipes made by hand lay-up, and filament winding process were also thoroughly analyzed. Kumar et al. [16] proposed a utility concept for multi-response optimization in turning uni-directional glass fiber-reinforced plastics composite using a carbide cutting tool. A multi-response optimization problem has been converted to an equivalent single objective optimization problem, which has been further solved by the Taguchi methodology [17]. The work of Hussain et al. [18] investigated some aspects on machinability, such as surface roughness and cutting force, in turning of GFRP composite materials for a range of fiber orientation angles $\left(30-90^{\circ}\right)$ with a Cubic Boron Nitride (CBN) cutting tool insert using fuzzy rule-based optimization of multiple responses. 
Maintaining the surface quality of machined FRP materials is a demanding task. In order to understand the surface morphology and study the dimensional properties, it is necessary to characterize and quantify the quality of the machined surface and the effect of process parameters on the surface quality. Raveendran et al. [19] used grey relational analysis, desirability function analysis, and analysis of variance approach for optimization purposes and they mainly focused on the effective turning of GFRP using TiCN/TiN-coated tool. In addition, in other research work [20], the influence of cutting parameters and insert radius on the cutting force and surface roughness of GFRP material during machining was investigated, where it was observed that high cutting speeds and low feed rates provide the best surface quality in the turning process of GFRP composite materials. In another study [21], an attempt has been made to investigate the machining characteristics of GFRP composite tubes of different fiber orientations with various process parameters and surface roughness $(\mathrm{Ra})$ and machining time were analyzed using Analysis of Variance (ANOVA). In addition, in another investigation [22], a relatively novel module was applied for multi response optimization in turning of glass fiber reinforced epoxy composites using Grey coupled artificial neural network model towards optimizing of cutting force, surface roughness, and material removal rate. Equbal et al. [23] performed a multi-response optimization procedure, to achieve the optimal setting of the cutting parameters by using a combination of Artificial Neural Network (ANN) and Genetic Algorithm (GA). ANN was used to establish the relationship between the input and output parameters, and verification of the network showed that the neural network produced accurate results for obtaining objective value from any set of input parameters. The genetic algorithm was used to generate the Pareto optimal solutions.

In addition, the Response Surface Methodology (RSM) has been utilized in the past to develop statistically-based models for the prediction of the surface roughness during machining. The RSM is a recognized mathematical tool that can be used to investigate the relationship between a number of input variables and one or more responses (outputs). Several machining-related studies exist in the literature where RSM has been implemented successfully. Subramanian et al. [24] developed a statistical model to predict surface roughness with respect to rake angle, nose radius of cutting tool, and machining parameters, such as cutting speed, feed rate, and depth of cut. Efkolidis et al. [25] used RSM and similar methodologies to predict the thrust force and torque generated during drilling of A17075. Similarly, Tzotzis et al. [26] established statistical models for the machining force components induced when hard turning AISI4140. Moreover, Malakizadi et al. [27] developed prediction models, by combining RSM with numerical investigation, for the flank wear evolution of tool.

In the current work, the influence of cutting conditions (cutting speed, feed rate, and depth of cut) on surface integrity evolution has been studied on turning Filament Winding GFRP Pipe Rings. The main goal was to investigate the difference of surface roughness for various turning conditions. Initially, the experimental details of the proposed cutting model are presented, as well as the experimental data obtained using a Computer Numerical Control (CNC) machine during an internal turning process. Thereafter, the influence of the cutting parameters on surface quality is presented by microscopic examination. Modeling of roughness based on statistical method is also presented while the roughness measurements, once performed, are recorded and analyzed using a statistical technique. Finally, conclusions summarize the results and contributions of this study.

\section{Experimental Details}

Glass Fiber Reinforced Polymer (GFRP) tubes were manufactured using CAMELYAF ${ }^{\circledR}$ Tex 1200 E-Glass fibers supplied as bobbins for direct roving and HUNTSMAN ARALDITE ${ }^{\circledR}$ LY 556 resin with ARADUR ${ }^{\circledR} 917 \mathrm{CH}$ hardener and DY 070 accelerator (100:90:5). All tubes were manufactured using a filament winding machine. During the production, the tension of the fiber tows was monitored and kept constant $(15 \mathrm{~N})$ using a computer based tensioning system. The pipes were produced on a steel mandrel which was covered by a thick 
layer of mold release agent to facilitate the mandrel extraction. After the winding, the tubes were cured for $4 \mathrm{~h}$ at $80^{\circ} \mathrm{C}$ and post-cured for $8 \mathrm{~h}$ at $140{ }^{\circ} \mathrm{C}$. The volume fraction of the tubes $55 \%$ fibers and $45 \%$ resin. The samples were produced in a length of approximately $1500 \mathrm{~mm}$ and then cut to rings of $20 \mathrm{~mm}$ width with outside diameter $\mathrm{D}_{\text {out }} 56 \mathrm{~mm}$ and inside diameter $D_{\text {in }} 50 \mathrm{~mm}$ for subsequent turning, as shown in Figure 1a. The length of the rings was selected as $20 \mathrm{~mm}$ since the support of each ring is more stable in chuck during internal turning. All the samples were accurately examined to verify the absence of delamination close to the cut edges.

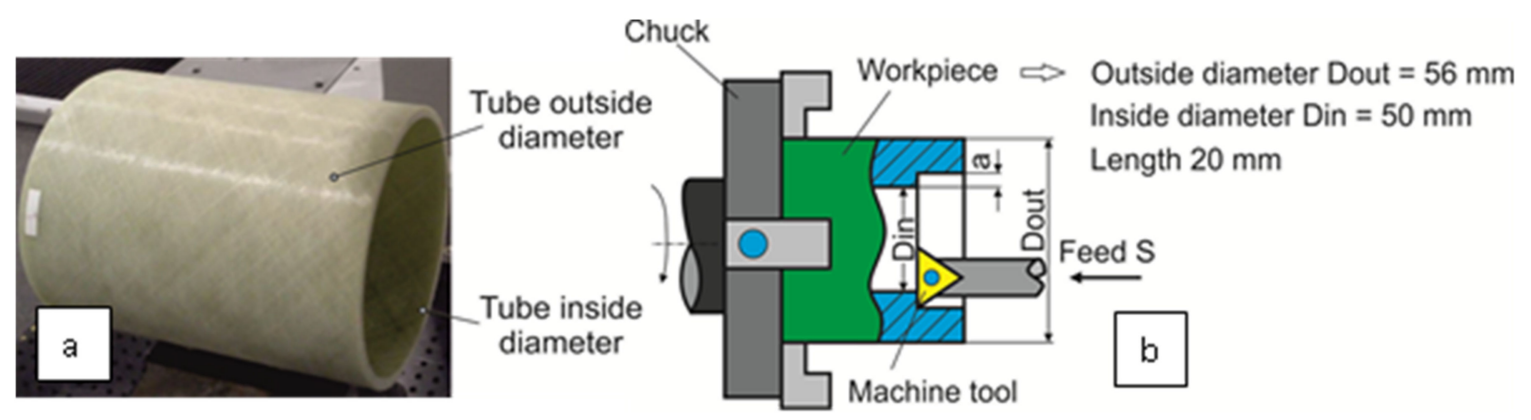

Figure 1. (a) Filament winding pipe; (b) turning experiment with cutting parameters.

The cutting experiments were carried out on a Chevalier PCL 1840 CNC machine using a Poly Crystalline Diamond insert (Kennametal A12SSTLCR3, Pittsburgh, PA, USA). The specimens were turned separately (Figure $1 \mathrm{~b}$ ) using internal machining. The cutting speed $V$ was selected with three different values $75,100,125 \mathrm{~mm} / \mathrm{min}$, the feed rate $S$ with the values of $0.1,1.15,0.2 \mathrm{~mm} / \mathrm{rev}$ and the depth of cut (a) with three values, as well 0.5 , $1 \mathrm{~mm}$, and $1.5 \mathrm{~mm}$. Each sample was turned and the surface roughness test was carried out on each turned surface. The surface roughness has been captured in three dimensions by the optical (confocal) 3D measurement system $\mu$ surf (Nanofocus, Oberhausen, Germany), and the cut of length measurement was $0.25 \mathrm{~mm}$.

\section{Influence of Cutting Parameters on Surface Morphology}

Table 1 contains all the important cutting conditions used in the experiments performed in this study, as well as the measured values for the average maximum height of the profile $R_{z}$ and the average roughness $R_{a}$. It should be noted that the orientation of the winding fibers was $\pm 45^{\circ}$; thereby, the effect of fiber angle on the surface roughness values was not a parameter that has been studied in the current work. The measurements of $R_{a}$ and $R_{z}$ were performed on the internal diameter of rings at four locations spaced $90^{\circ}$ each, where a mean value of the measurements was calculated. It seems that the increase in cutting speed from $75 \mathrm{~m} / \mathrm{min}$ to $100 \mathrm{~m} / \mathrm{min}$ has detrimental effect on both surface roughness $R_{a}$ and $R_{z}$ values despite the fact that, when cutting speed increases from $100 \mathrm{~m} / \mathrm{min}$ to $125 \mathrm{~m} / \mathrm{min}$, that decrease is smaller. In addition, the increase in feed rate results in small increase in the roughness values, especially when the feed rises from $0.1 \mathrm{~mm} / \mathrm{rev}$ to $0.15 \mathrm{~mm} / \mathrm{rev}$. However, when the feed shifts from $0.15 \mathrm{~mm} / \mathrm{rev}$ to $0.2 \mathrm{~mm} / \mathrm{rev}$ the results are mixed with noticeable differences. The results from the changes of the depth of cut show a peculiar response since, for low speed of $75 \mathrm{~m} / \mathrm{min}$, the roughness values are decreasing; however, for all other cutting conditions, the roughness values are increasing. It seems that, in order to obtain low values of roughness, the most critical parameter is the cutting speed. The best values of Ra obtained for the cutting conditions of $V=75 \mathrm{~m} / \mathrm{min}$, $S=0.1 \mathrm{~mm} / \mathrm{rev}$, and a $=1.5 \mathrm{~mm}$. The relationship between the surface roughness and cutting parameters, which is further discussed in Section 4, is caused by the inhomogeneous microstructure of reinforcing fibers in the composite material, which results in surface details including deformations and fractures at micro level. A typical surface profile from observed in turning of GFRP composites is presented in Figure 2. It represents a schematic of the 3D surface profile from the 3D measurement system $\mu$ surf with cutting 
conditions in case of Figure 2a as $V=75 \mathrm{~mm} / \mathrm{min}, S=0.15 \mathrm{~mm} / \mathrm{rev}, a=1.5 \mathrm{~mm}$, as well as for Figure $2 \mathrm{~b}$ as $V=100 \mathrm{~mm} / \mathrm{min}, S=0.15 \mathrm{~mm} / \mathrm{rev}, a=0.5 \mathrm{~mm}$. These images are obtained when measuring surface roughness on the machined material, and they represent different roughness profiles with peak values of $50 \mu \mathrm{m}$ and $80 \mu \mathrm{m}$. The orientation of the fibers after machining is clearly seen, especially in Figure 2b, where the lower left corner shows the winding fibers in $+45^{\circ}$ direction as compared with the rest of the images that the fibers are oriented at $-45^{\circ}$. The distribution of fibers is not even, and there is probably a preferential removal of fibers in the composite materials during machining. Figure 3 shows a typical scanning electron micrograph (SEM Phenom ProX) of the machining surface with cutting conditions of $V=75 \mathrm{~m} / \mathrm{min}, S=0.1 \mathrm{~mm} / \mathrm{rev}$, and $a=1.5 \mathrm{~mm}$. All surfaces had comparable appearance irrespective of the machining parameters. No damage-free surfaces were obtained in the current work. Figure 3a shows a poor surface finish due to mainly debonding and brittle breakage of fibers, which is similar to the scanning electron micrographs obtained in another study [15]. There were fiber ends sticking out, peaks of deformed matrix material, and tensile and shear patterns of fibers fracture, as well as debonding between fibers and matrix. Figure $3 b$ shows a magnification of the surface near fiber ends revealing the detrimental effect of the machining on the fibers.

Table 1. Cutting conditions, coded values, and experimental results.

\begin{tabular}{|c|c|c|c|c|c|c|c|c|c|c|c|}
\hline Standard Order & $\begin{array}{c}V \\
(\mathrm{~m} / \mathrm{min})\end{array}$ & $\begin{array}{c}S \\
(\mathrm{~mm} / \mathrm{rev})\end{array}$ & $\begin{array}{c}a \\
(\mathrm{~mm})\end{array}$ & $V^{2}$ & $S^{2}$ & $a^{2}$ & $V \times S$ & $V \times a$ & $S \times a$ & $\begin{array}{c}R_{a} \\
(\mu \mathrm{m})\end{array}$ & $\begin{array}{c}R_{z} \\
(\mu \mathrm{m})\end{array}$ \\
\hline 1 & \multirow{9}{*}{75} & \multirow{3}{*}{0.1} & 0.5 & \multirow{9}{*}{5625} & \multirow{3}{*}{0.01} & 0.25 & \multirow{3}{*}{7.5} & 37.5 & 0.05 & 12.506 & 61.499 \\
\hline 2 & & & 1 & & & 1 & & 75 & 0.1 & 11.12 & 46.03 \\
\hline 3 & & & 1.5 & & & 2.25 & & 112.5 & 0.15 & 10.925 & 47.58 \\
\hline 4 & & & 0.5 & & \multirow{3}{*}{0.0225} & 0.25 & \multirow{3}{*}{11.25} & 37.5 & 0.075 & 14.421 & 61.27 \\
\hline 5 & & 0.15 & 1 & & & 1 & & 75 & 0.15 & 13.15 & 48.179 \\
\hline 6 & & & 1.5 & & & 2.25 & & 112.5 & 0.225 & 11.898 & 43.18 \\
\hline 7 & & \multirow{3}{*}{0.2} & 0.5 & & \multirow{3}{*}{0.04} & 0.25 & \multirow{3}{*}{15} & 37.5 & 0.1 & 15.342 & 67.46 \\
\hline 8 & & & 1 & & & 1 & & 75 & 0.2 & 11.507 & 54.409 \\
\hline 9 & & & 1.5 & & & 2.25 & & 112.5 & 0.3 & 13.294 & 53.551 \\
\hline 10 & \multirow{9}{*}{100} & \multirow{3}{*}{0.1} & 0.5 & \multirow{9}{*}{10,000} & \multirow{3}{*}{0.01} & 0.25 & \multirow{3}{*}{10} & 50 & 0.05 & 18.102 & 63.535 \\
\hline 11 & & & 1 & & & 1 & & 100 & 0.1 & 18.66 & 67.92 \\
\hline 12 & & & 1.5 & & & 2.25 & & 150 & 0.15 & 19.796 & 76.584 \\
\hline 13 & & & 0.5 & & \multirow{3}{*}{0.0225} & 0.25 & \multirow{3}{*}{15} & 50 & 0.075 & 22.04 & 81.78 \\
\hline 14 & & 0.15 & 1 & & & 1 & & 100 & 0.15 & 23.04 & 85.41 \\
\hline 15 & & & 1.5 & & & 2.25 & & 150 & 0.225 & 23.408 & 78.93 \\
\hline 16 & & \multirow{3}{*}{0.2} & 0.5 & & \multirow{3}{*}{0.04} & 0.25 & \multirow{3}{*}{20} & 50 & 0.1 & 22.106 & 73.261 \\
\hline 17 & & & 1 & & & 1 & & 100 & 0.2 & 21 & 83.279 \\
\hline 18 & & & 1.5 & & & 2.25 & & 150 & 0.3 & 25.229 & 93.02 \\
\hline 19 & \multirow{9}{*}{125} & \multirow{3}{*}{0.1} & 0.5 & \multirow{9}{*}{15,625} & \multirow{3}{*}{0.01} & 0.25 & \multirow{3}{*}{12.5} & 62.5 & 0.05 & 15.04 & 48.113 \\
\hline 20 & & & 1 & & & 1 & & 125 & 0.1 & 15.874 & 59.036 \\
\hline 21 & & & 1.5 & & & 2.25 & & 187.5 & 0.15 & 18.67 & 68.38 \\
\hline 22 & & & 0.5 & & \multirow{3}{*}{0.0225} & 0.25 & \multirow{3}{*}{18.75} & 62.5 & 0.075 & 16.932 & 57.142 \\
\hline 23 & & 0.15 & 1 & & & 1 & & 125 & 0.15 & 20.11 & 71.69 \\
\hline 24 & & & 1.5 & & & 2.25 & & 187.5 & 0.225 & 24.96 & 91.52 \\
\hline 25 & & \multirow{3}{*}{0.2} & 0.5 & & \multirow{3}{*}{0.04} & 0.25 & & 62.5 & 0.1 & 16.376 & 56.666 \\
\hline 26 & & & 1 & & & 1 & 25 & 125 & 0.2 & 20.952 & 74.797 \\
\hline 27 & & & 1.5 & & & 2.25 & & 187.5 & 0.3 & 23.915 & 88.41 \\
\hline
\end{tabular}




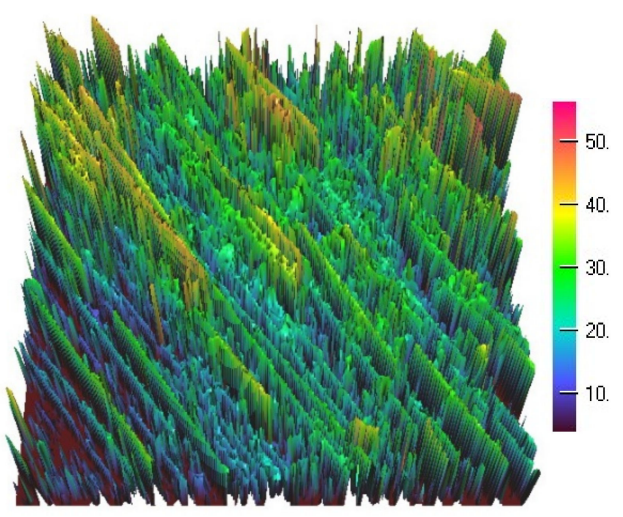

(a)

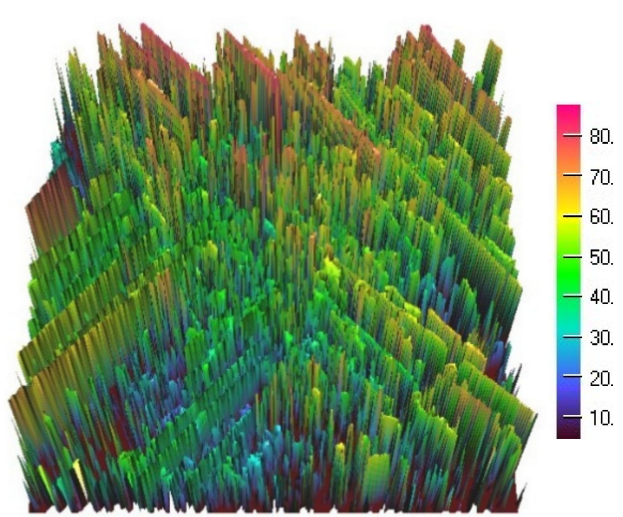

(b)

Figure 2. Typical three-dimensional surface profile $(\mu \mathrm{m})$ showing (a) the orientation of the winding fibers in $-45^{\circ}$ for $V=75 \mathrm{~mm} / \mathrm{min}, S=0.15 \mathrm{~mm} / \mathrm{rev}, a=1.5 \mathrm{~mm}$ and $(\mathbf{b})$ the orientation of the winding fibers in $+45^{\circ}$ (lower left) and $-45^{\circ}$ for $V=100 \mathrm{~mm} / \mathrm{min}, S=0.15 \mathrm{~mm} / \mathrm{rev}, a=0.5 \mathrm{~mm}$.

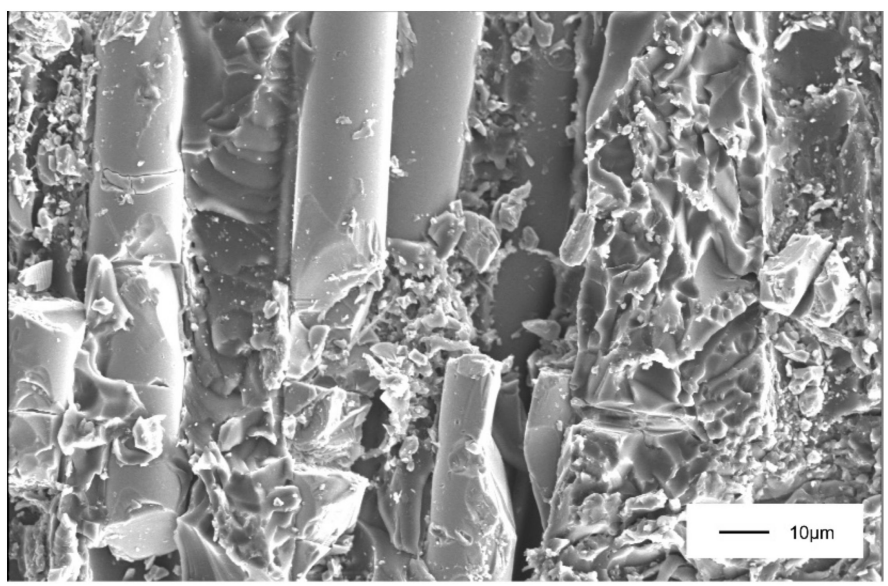

(a)

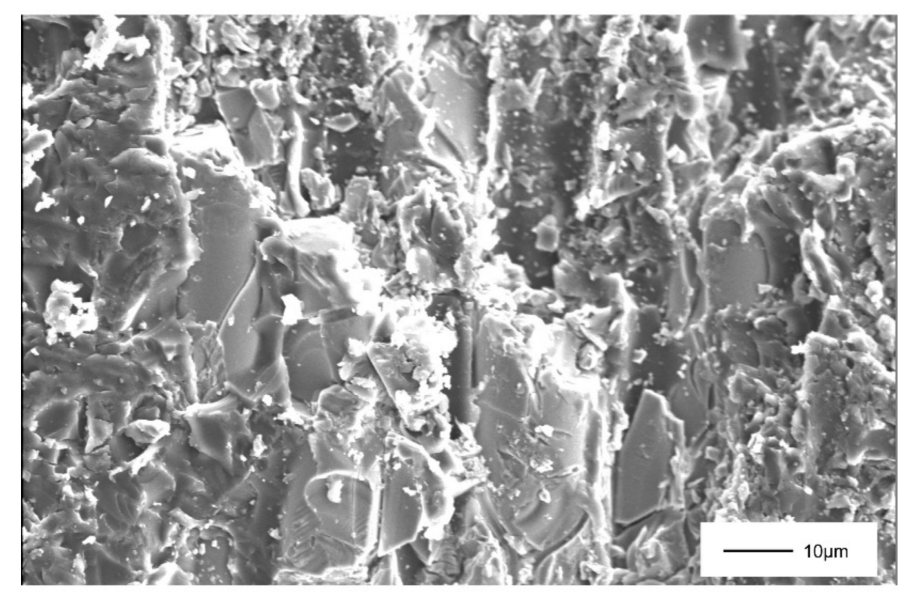

(b)

Figure 3. Typical scanning electron microscope of machined surfaces for cutting conditions of $V=75 \mathrm{~m} / \mathrm{min}, S=0.1 \mathrm{~mm} / \mathrm{rev}$ and $a=1.5 \mathrm{~mm}$ at (a) low and (b) high magnification.

\section{Modeling of Roughness Based on Statistical Methodologies}

The mathematical models for the surface roughness were developed based on the experimental results. The parameters that were involved in the present study are the cutting speed, the feed and the depth of cut. Thus, the fit of the regression models was done based on the aforementioned factors. Table 1 contains all the important cutting conditions used in the experiments performed in this study, the coded values of the produced mathematical 
models, and the measured values for the average maximum height of the profile $R_{z}$ and the average roughness $R_{a}$. The measurements of $R_{a}$ and $R_{z}$ were performed on the internal diameter of rings at four locations spaced $90^{\circ}$ each and the mean value of the measurements is shown in Table 1. Equation (1) represents the second order polynomial that is produced by the regression analysis. The $Y$ variable is the response of the model, whereas the $X_{i}$ values are the predictors (in this case, the three key parameters, cutting speed, feed, and depth of cut). Finally, the $b_{i}$ values are the regression coefficients.

$$
Y=b_{0}+b_{1} X_{1}+b_{2} X_{2}+b_{3} X_{3}+b_{4} X_{1}^{2}+b_{5} X_{2}^{2}+b_{6} X_{3}^{2}+b_{7} X_{1} X_{2}+b_{8} X_{1} X_{3}+b_{7} X_{2} X_{3}
$$

With the implementation of the experimental results and the previously stated polynomial, Equations (2) and (3) were generated for the prediction of the average maximum height of the profile $R_{z}(\mu \mathrm{m})$ and the average roughness $R_{a}(\mu \mathrm{m})$, respectively.

$$
\begin{gathered}
R_{z}=-149+4.66 V+262 S-103 a-0.0274 V^{2}-1215 S^{2}+6.75 a^{2}+1.60 V S+0.882 V a+60.7 S a \\
R_{a}=-72.8+1.67 V+172 S-23.5 a-0.00887 V^{2}-656 S^{2}+3.14 a^{2}+0.404 V S+0.169 V a+16.2 S a
\end{gathered}
$$

where $R_{z}$ is the average maximum peak to valley of five consecutive sampling lengths within the measuring in $\mu \mathrm{m}, R_{a}$ is the average roughness in $\mu \mathrm{m}, V$ is the cutting speed in $\mathrm{m} / \mathrm{min}, S$ is the feed in $\mathrm{mm} / \mathrm{rev}$, and $a$ is the depth of cut in $\mathrm{mm}$.

With the processing of the results that are presented in Table 1 , the next charts were plotted for visualizing the comparison between the experimental and the predicted values of surface roughness, as illustrated in Figure 4 . These charts present the mean values of the $R_{a}$ (Figure $4 \mathrm{a}$ ) and the $R_{z}$ (Figure $4 \mathrm{~b}$ ), for both the experiments and the prediction model.

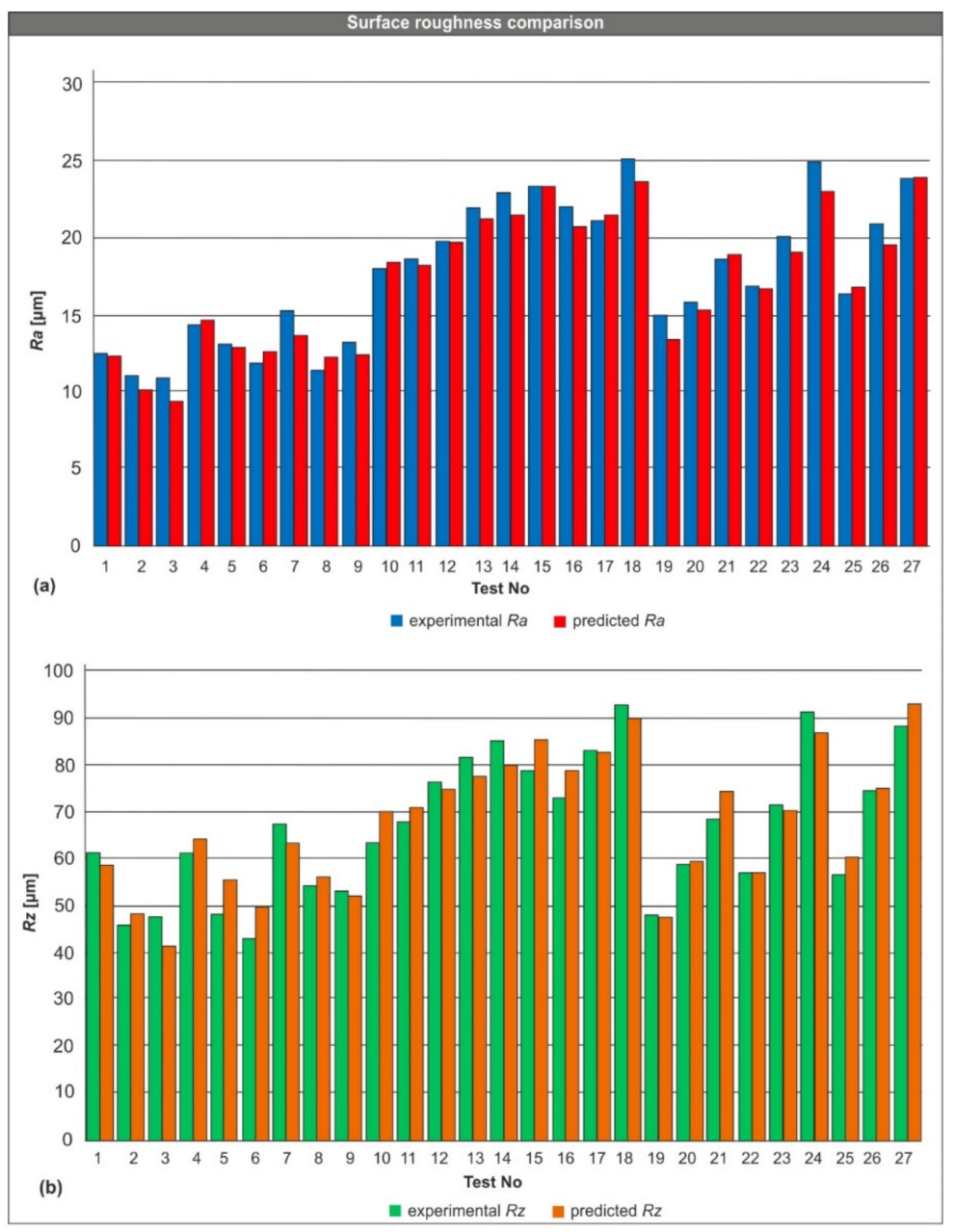

Figure 4. Comparison between the experimental and the predicted values of (a) $R_{a}$ and (b) $R_{z}$. 
In order to validate the models, ANOVA has been performed with a confidence level of $95 \%$. The adjusted R-square was found to be very high in both cases $(88 \%$ and $95.2 \%$, respectively) which proves the validity of the fit. Because the used significance level was 0.05 , the factors that contribute the most to the derived models are those with a $p$-value smaller than 0.05. According to the values found in Table 2, such contributors for the $R_{z}$ model are: $V, a, V^{2}$ and $V \times a$, all with a $p$-value of 0.000 and the constant of the model with a $p$-value of 0.004 . Similarly for the case of $R_{a}$, the main contributors based on the values found in Table 3 are: the constant, $V, a, V^{2}$ and $V \times a$, all with a $p$-value of 0.000 and $S^{2}$ with a $p$-value of 0.001 . The fact that the $p$-value of the analysis for both cases is 0.000 further enhances the adequacy of the models. The accuracy of the models was evaluated with the utilization of a residual analysis. Figures 5 and 6 each contain four different graphs that relate to the $R_{z}$ and $R_{a}$ values accordingly: the normal probability plot (Figures 5a and 6a), the residuals versus the fitted values (Figures $5 b$ and $6 b$ ), the histogram of the residuals (Figures $5 \mathrm{c}$ and $6 \mathrm{c}$ ), and the residuals versus the order of the data (Figures $5 \mathrm{~d}$ and $6 \mathrm{~d}$ ). It is obvious that all plots present a normality in distribution, which indicates a strong validity of the regression models.

Table 2. Analysis of Variance (ANOVA) results for the maximum height of the profile $R_{a}$.

\begin{tabular}{|c|c|c|c|c|c|}
\hline Source & Degree of Freedom & Sum of Squares & Mean Square & $f$-Value & $p$-Value \\
\hline Regression & 9 & 5248.31 & 583.15 & 22.25 & 0.000 \\
\hline Residual Error & 17 & 445.49 & 26.21 & & \\
\hline Total & 26 & 5693.79 & & & \\
\hline \multicolumn{6}{|c|}{ R-sq $($ adj $)=88.0 \%$} \\
\hline Term & PE Coefficient & \multicolumn{2}{|c|}{ SE Coefficient } & $t$-Value & $p$-Value \\
\hline Constant & -149.39 & \multicolumn{2}{|c|}{44.21} & -3.38 & 0.004 \\
\hline V & 4.6572 & \multicolumn{2}{|c|}{0.7036} & 6.62 & 0.000 \\
\hline$S$ & 261.6 & \multicolumn{2}{|c|}{284.5} & 0.92 & 0.371 \\
\hline$a$ & -102.98 & \multicolumn{2}{|c|}{22.44} & -4.59 & 0.000 \\
\hline$V^{2}$ & -0.027425 & \multicolumn{2}{|c|}{0.003344} & -8.20 & 0.000 \\
\hline$S^{2}$ & -1214.9 & \multicolumn{2}{|c|}{835.9} & -1.45 & 0.164 \\
\hline$a^{2}$ & 6.751 & \multicolumn{2}{|c|}{8.359} & 0.81 & 0.430 \\
\hline$V \times S$ & 1.602 & \multicolumn{2}{|c|}{1.182} & 1.36 & 0.193 \\
\hline$V \times a$ & 0.8820 & \multicolumn{2}{|c|}{0.1182} & 7.46 & 0.000 \\
\hline$S \times a$ & 60.66 & \multicolumn{2}{|c|}{59.11} & 1.03 & 0.319 \\
\hline
\end{tabular}

Table 3. Analysis of Variance (ANOVA) results for the average roughness $R_{z}$.

\begin{tabular}{|c|c|c|c|c|c|}
\hline Source & Degree of Freedom & Sum of Squares & Mean Square & $f$-Value & $p$-Value \\
\hline Regression & 9 & 521.308 & 57.923 & 58.29 & 0.000 \\
\hline Residual Error & 17 & 16.892 & 0.994 & & \\
\hline Total & 26 & 538.201 & & & \\
\hline \multicolumn{6}{|c|}{ R-sq $(\operatorname{adj})=95.2 \%$} \\
\hline Term & PE Coefficient & \multicolumn{2}{|c|}{ SE Coefficient } & $t$-Value & $p$-Value \\
\hline Constant & -72.849 & \multicolumn{2}{|c|}{8.609} & -8.46 & 0.000 \\
\hline$V$ & 1.6744 & \multicolumn{2}{|c|}{0.1370} & 12.22 & 0.000 \\
\hline$S$ & 172.26 & \multicolumn{2}{|c|}{55.40} & 3.11 & 0.006 \\
\hline$a$ & -23.480 & \multicolumn{2}{|c|}{4.370} & -5.37 & 0.000 \\
\hline$V^{2}$ & -0.0088684 & \multicolumn{2}{|c|}{0.0006511} & -13.62 & 0.000 \\
\hline$S^{2}$ & -655.6 & \multicolumn{2}{|c|}{162.8} & -4.03 & 0.001 \\
\hline$a^{2}$ & 3.141 & \multicolumn{2}{|c|}{1.628} & 1.93 & 0.071 \\
\hline$V \times S$ & 0.4045 & \multicolumn{2}{|c|}{0.2302} & 1.76 & 0.097 \\
\hline$V \times a$ & 0.16899 & \multicolumn{2}{|c|}{0.02302} & 7.34 & 0.000 \\
\hline$S \times a$ & 16.24 & \multicolumn{2}{|c|}{11.51} & 1.41 & 0.176 \\
\hline
\end{tabular}




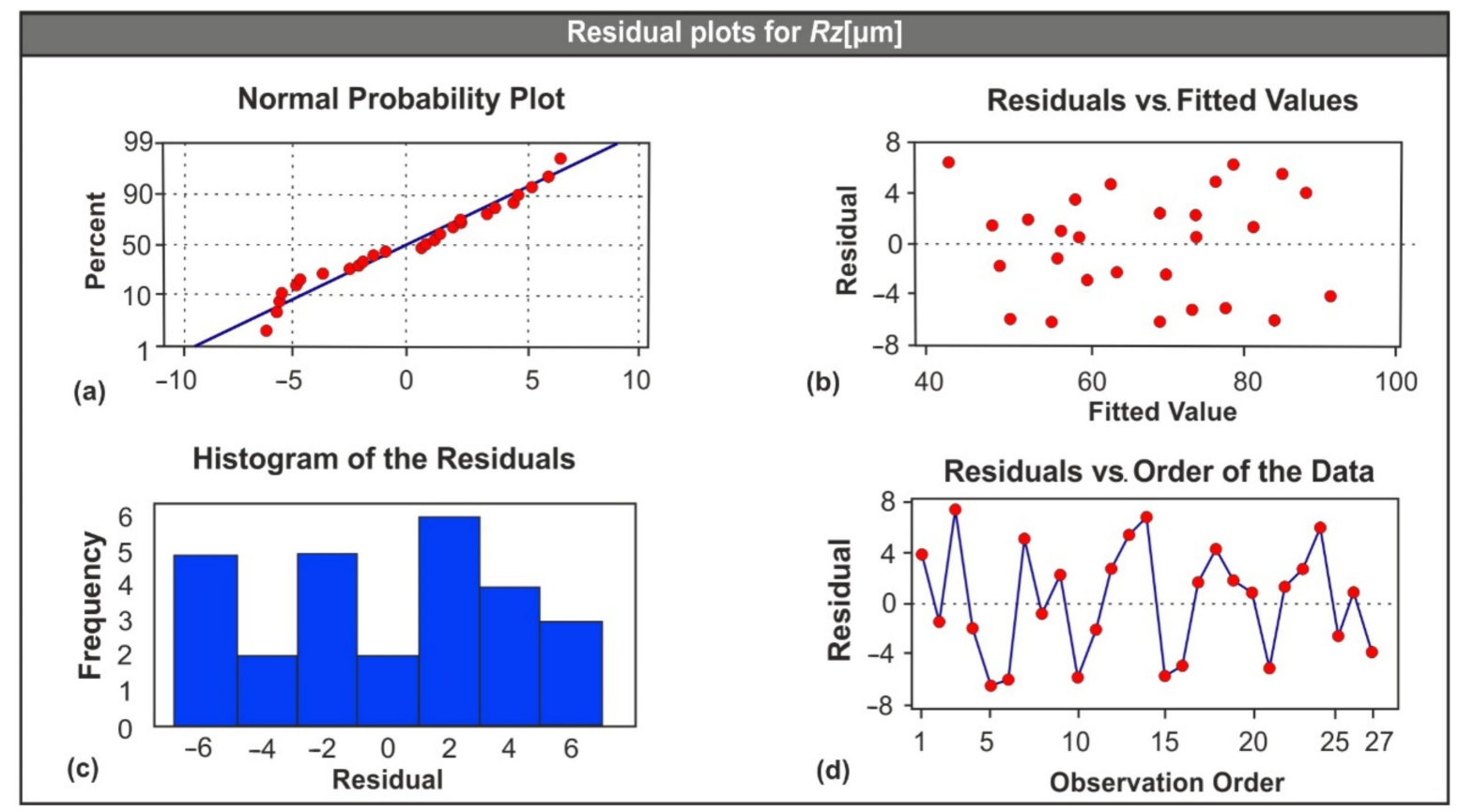

Figure 5. Residual analysis for the maximum height of the profile $R_{a}$. (a) The normal probability plot; (b) Residuals vs. fitted values; (c) Histogram of the residuals; (d) Residuals vs. order of the data.

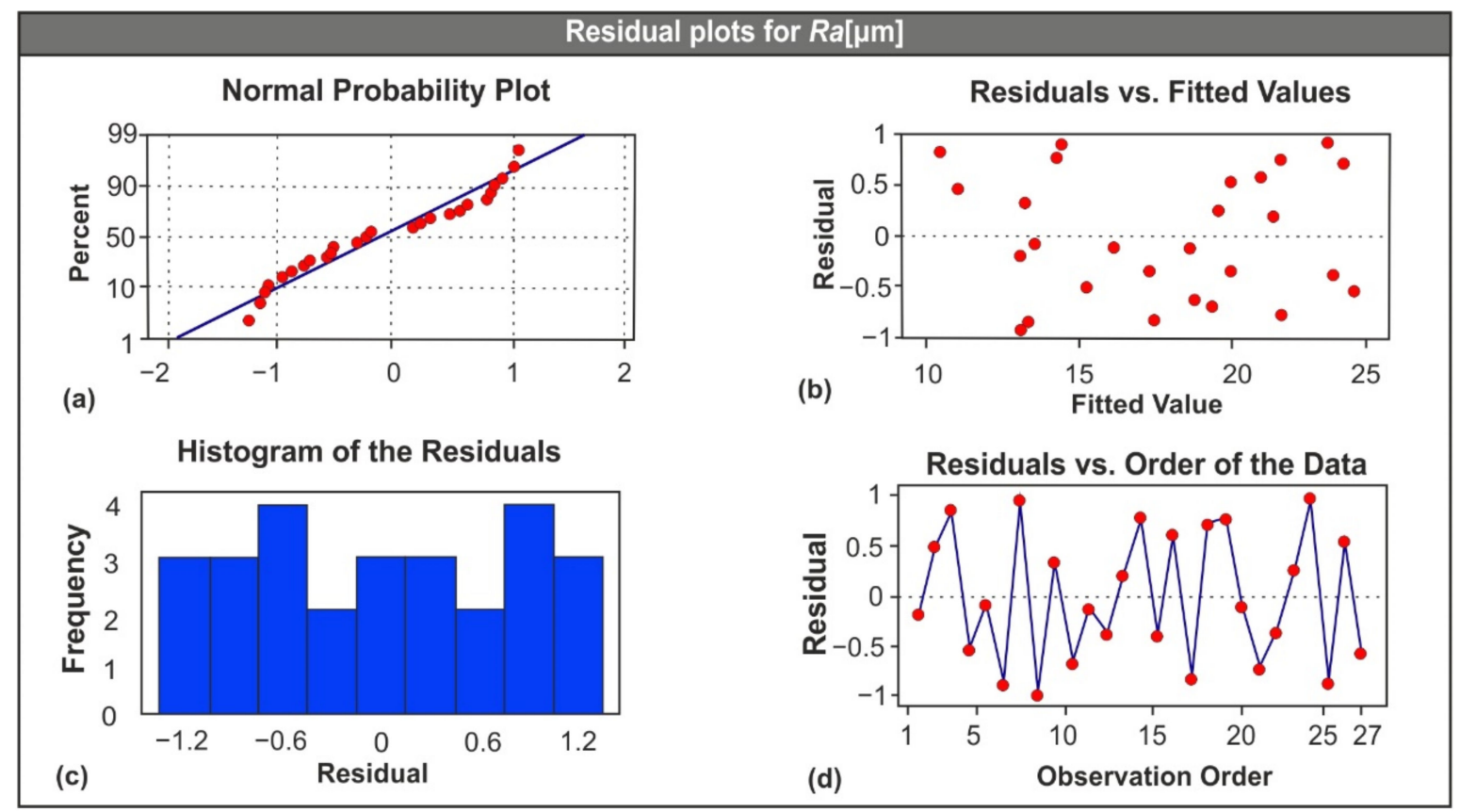

Figure 6. Residual analysis for the average roughness $R_{z}$. (a) The normal probability plot; (b) Residuals vs. fitted values; (c) Histogram of the residuals; (d) Residuals vs. order of the data.

The normal probability plot of the residuals for both the $R_{z}$ and $R_{a}$ shows that the observed values are close to the fitted line and there is no evidence of significant variation. The scatter plot of the residuals versus the fitted values for both $R_{z}$ and $R_{a}$ points out that the residuals do not follow any specific pattern; rather, they are scattered on both sides arbitrarily. Moreover, the residuals versus the order of the data plots suggests that there are no systematic errors present in the system.

Finally, the histogram of the residuals depicts the distribution of the residuals based on their appearance in the observations. Both Figures 5 and 6 indicate that there is no major 
skewness present. Upon validation of both mathematical models with the aid of ANOVA, the model-based values of $R_{z}$ and $R_{a}$ were generated for comparison purposes.

Figure 7 illustrates this comparison: the blue line indicates the modeled values for $R_{z}$, whereas the orange line represents the experimental values for $R_{z}$. Similarly, the red line of the plot depicts the modeled values of $R_{a}$ and the green line stands for the experimental values of $R_{a}$. The values of all four lines in the plot follow the same order of the experiments. It is clear that the correlation between the experimental results and the modeled values is very high. The relative error for the $R_{z}$ fluctuates between $-12.9 \%$ and $15.6 \%$. However, seven cases exhibit an error at the range of $-0.7 \%$ and $0.8 \%$. Examining the relative error for the $R_{a}$, it is found to be between $-13.2 \%$ and $7.2 \%$. In addition, an error ranging from $-2 \%$ to $2.8 \%$ is present in almost half of the cases.

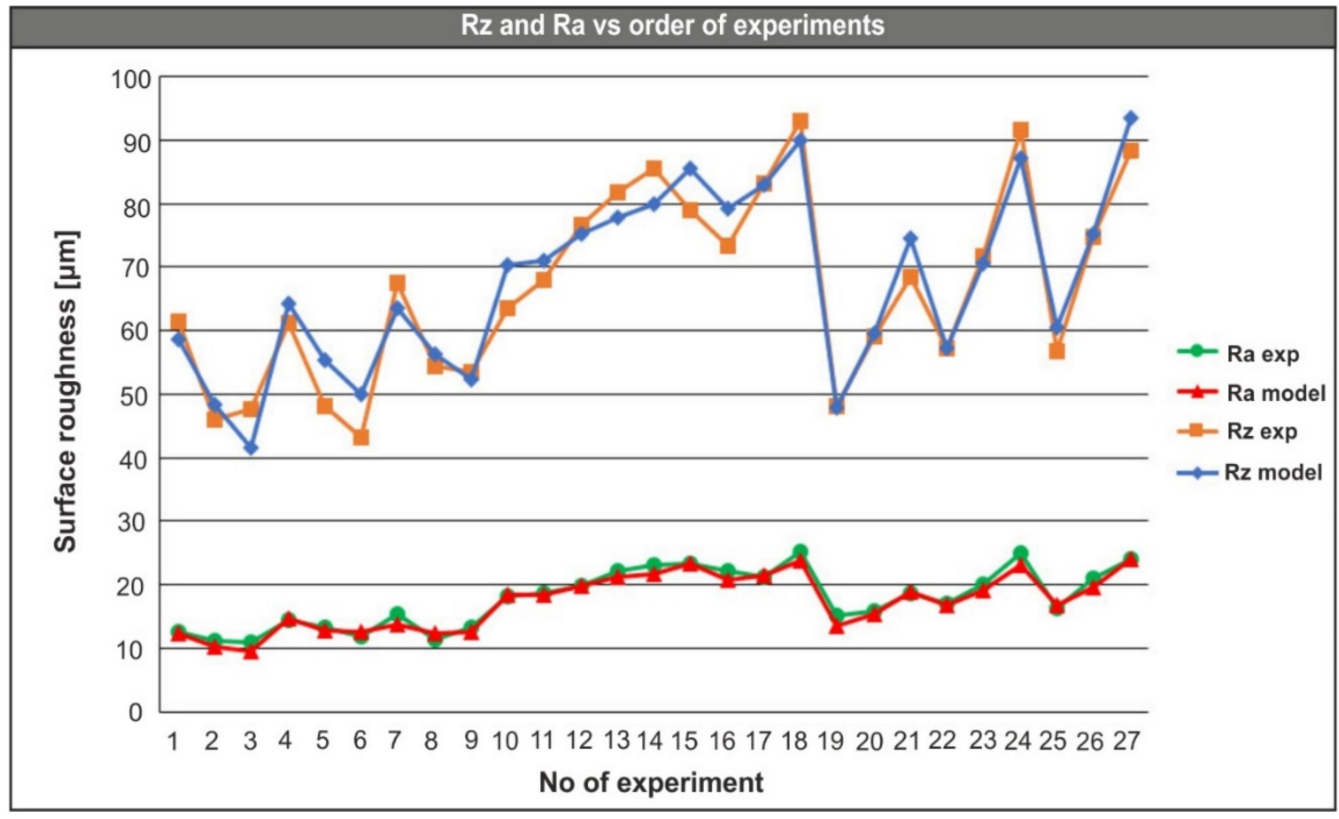

Figure 7. Comparison plot of experimental and modeled values of $R_{z}$ and $R_{a}$.

In addition to ANOVA, the Analysis of Means (ANOM) plots were included to visualize the statistically significant levels for each cutting parameter utilized in the present study. Figure 8 depicts the ANOM plots for both $R_{a}$ and $R_{z}$. It is pointed out that the means of levels one and two of the cutting speed are statistically different from the overall mean at significance level of 0.05 . Moreover, the variation of each mean (for all three levels of feed and depth of cut) from the overall mean is relatively short compared to the one for the levels of cutting speed. This fact, clearly indicates the strong influence of the cutting speed to the surface roughness.

Finally, analyzing the results of this paper can lead to the following conclusions. The shift in depth of cut (either from $0.5 \mathrm{~mm}$ to $1.0 \mathrm{~mm}$ or from $1.0 \mathrm{~mm}$ to $1.5 \mathrm{~mm}$ ) acts decreasingly to both $R_{z}$ and $R_{a}$ under certain conditions $(V=75 \mathrm{~m} / \mathrm{min}$ and $S=0.1 \mathrm{~mm} / \mathrm{rev}$ to $0.2 \mathrm{~mm} / \mathrm{rev}$ ). In contrast, for all other cutting conditions, the shift in depth of cut acts increasingly on both $R_{z}$ and $R_{a}$. Any change in feed has notable effect on roughness. When feed shifts from $0.1 \mathrm{~mm} / \mathrm{rev}$ to $0.15 \mathrm{~mm} / \mathrm{rev}, R_{a}$ is increased by approximately $16 \%$ on average. Similarly, $R_{z}$ increases about $11 \%$. Additionally, as the value of feed rises from $0.15 \mathrm{~mm} / \mathrm{rev}$ to $0.2 \mathrm{~mm} / \mathrm{rev}$, the effect on both $R_{a}$ and $R_{z}$ is mixed, with the percentage of change close to $10 \%$ in most cases. Other published research work reports the same trend, i.e., lower feed rates are beneficial for the surface quality of GFRP composites $[8,14,15]$. When cutting speed changes from $75 \mathrm{~m} / \mathrm{min}$ to $100 \mathrm{~m} / \mathrm{min}$, the resultant $R_{a}$ gains a significant increase of about $41 \%$ on average. On the contrary, when cutting speed increases from $100 \mathrm{~m} / \mathrm{min}$ to $125 \mathrm{~m} / \mathrm{min}, R_{a}$ decreases about $14 \%$, which is in accordance with 
other work [20]. The same trend applies to $R_{z}$ with the equivalent percentages at $30 \%$ and $17 \%$, respectively. Consequently, the validity of the generated mathematical models for both $R_{z}$ and $R_{a}$ is proved by the high level of fit (R-square value equal to $88 \%$ and $95.2 \%$, respectively). Moreover, the successful fit of both models is highlighted by the increased correlation between the experimental and the predicted values of roughness; the relative error was calculated ranging from $-12.9 \%$ to $15.6 \%$ for $R_{z}$ and from $-13.2 \%$ and $7.2 \%$ for $R_{a}$.
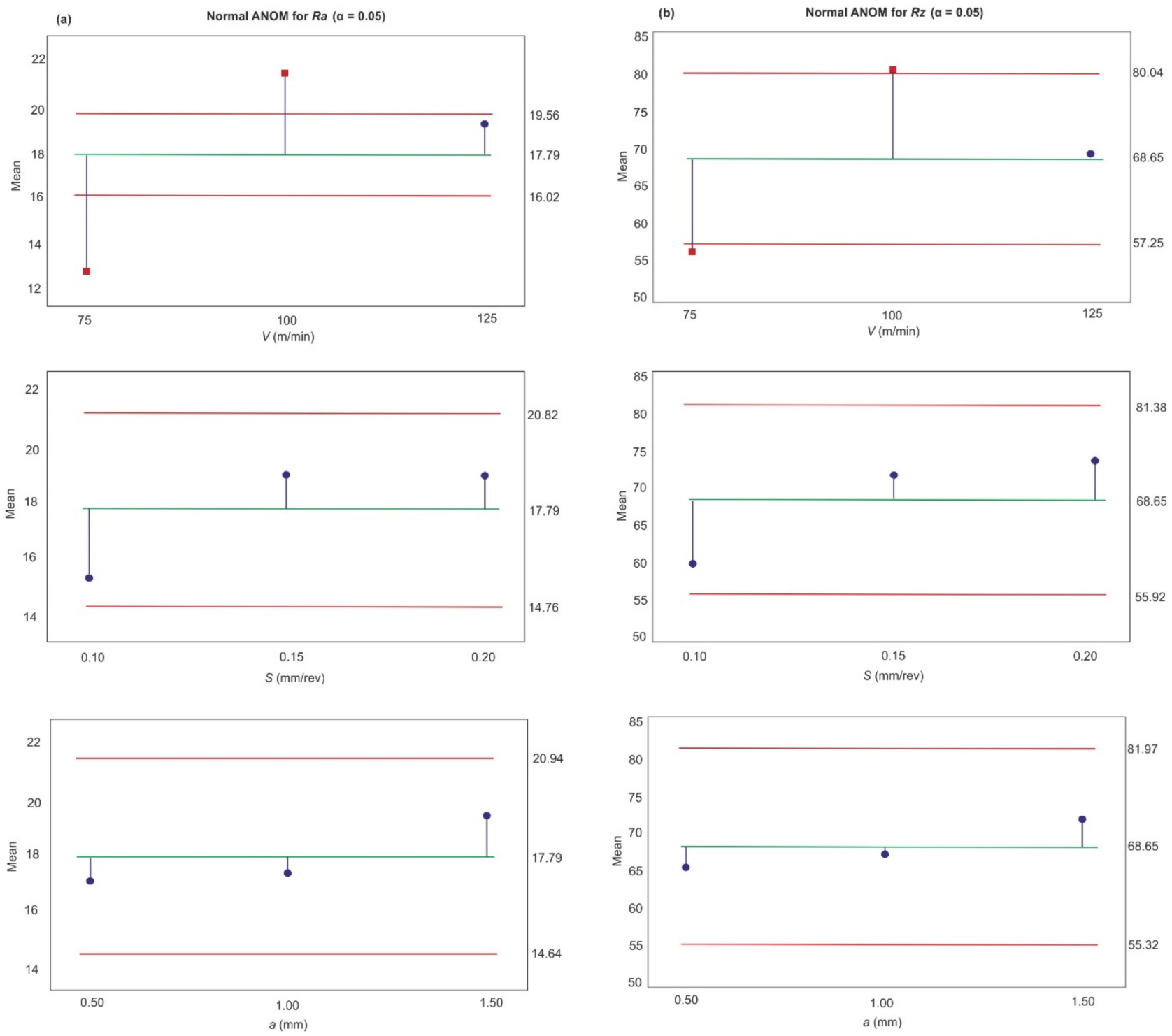

Figure 8. Analysis of Means (ANOM) plots for the surface roughness results; (a) $R_{a}$ and (b) $R_{z}$.

The developed prediction models were further analyzed by plotting their 3D response surfaces generated from the polynomial solutions (see Equations (2) and (3)). In other words, the data used to plot the surfaces are the ones used to solve the polynomials. Thus, the 3D plots can be used to visualize the combined effect of the investigated machining conditions (cutting speed, feed, and depth of cut) on the formed roughness. Figure $9 a, b$ illustrate the aforementioned 3D plots for $R_{z}$ and $R_{a}$, respectively, at each examined depth of cut $(0.50 \mathrm{~mm}, 1.00 \mathrm{~mm}$, and $1.50 \mathrm{~mm})$. 


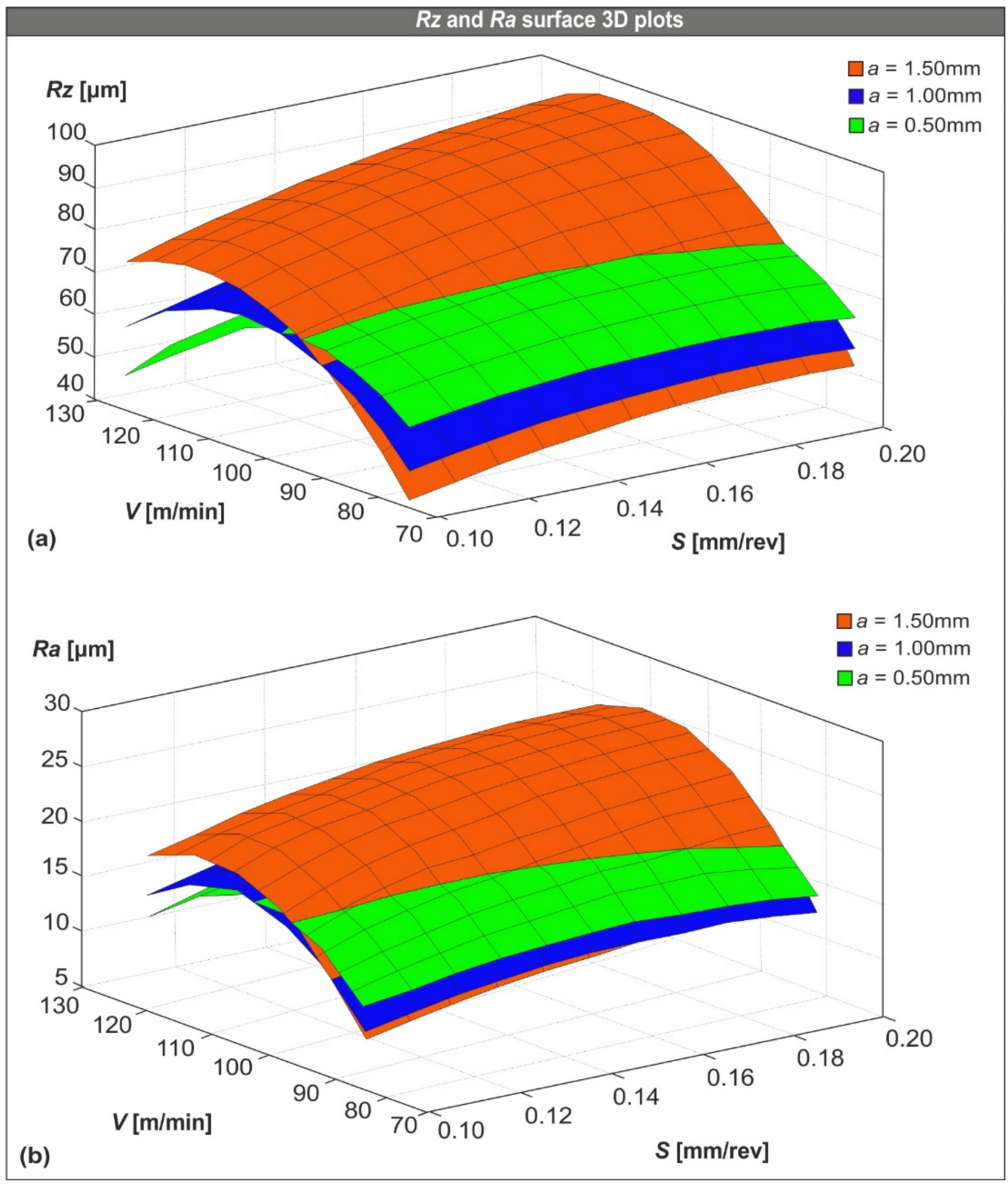

Figure 9. The 3D surface plots for $R_{z}(\mathbf{a})$ and $R_{a}(\mathbf{b})$.

Finally, three experiments were performed to further examine the validity of the prediction model by utilizing randomly selected conditions from within the range of the data applied in the present study. The applied cutting conditions are as follows: Test number one $(V=80 \mathrm{~m} / \mathrm{min}, S=0.14 \mathrm{~mm} / \mathrm{rev}$, and $a=0.9 \mathrm{~mm})$, test number two $(V=115 \mathrm{~m} / \mathrm{min}, S=0.11 \mathrm{~mm} / \mathrm{rev}$, and $a=1.4 \mathrm{~mm})$, and test number three $(V=120 \mathrm{~m} / \mathrm{min}$, $S=0.16 \mathrm{~mm} / \mathrm{rev}$, and $a=0.8 \mathrm{~mm}$ ). The results are presented in Table 4 , where it is highlighted that the relative error is low for all tests.

Table 4. Confirmation of prediction model.

\begin{tabular}{ccccccc}
\hline Test No & $\begin{array}{c}\text { Experimental } \\
\boldsymbol{R}_{\boldsymbol{a}}(\boldsymbol{\mu \mathrm { m } )}\end{array}$ & $\begin{array}{c}\text { Predicted } \\
\boldsymbol{R}_{\boldsymbol{a}}(\boldsymbol{\mu \mathrm { m } )}\end{array}$ & $\begin{array}{c}\text { Relative } \\
\text { Error }(\%)\end{array}$ & $\begin{array}{c}\text { Experimental } \\
\boldsymbol{R}_{\boldsymbol{z}}(\boldsymbol{\mu m})\end{array}$ & $\begin{array}{c}\text { Predicted } \\
\boldsymbol{R}_{\boldsymbol{z}}(\boldsymbol{\mu m})\end{array}$ & $\begin{array}{c}\text { Relative } \\
\text { Error }(\%)\end{array}$ \\
\hline I & 13.56 & 15.38 & 13.4 & 56.78 & 63.15 & 11.2 \\
II & 22.32 & 21.00 & -5.9 & 76.21 & 79.27 & 4.0 \\
III & 19.12 & 19.86 & 3.9 & 68.72 & 71.54 & 4.1 \\
\hline
\end{tabular}




\section{Conclusions}

In the current paper, an analysis of the surface quality in machining of composite materials in turning has been reported. The analysis concerned the machining of a glass fiber reinforced polymer composite rings manufactured by the filament winding process. The effects of machining parameters on the surface quality of the composites was analyzed using the effect graphs and microscopic examination. The results indicated that the maintenance of the surface quality of a composite is an important concern. It seems that at very low but also very high cutting speeds minimal surface roughness is obtained when machining the GFRP pipes. Medium cutting speeds increase the surface roughness. An increase of feed rate has a smaller effect on the increase surface roughness as compared to the cutting speed, while the effect of depth of cut has also a small effect showing an increased surface roughness as the depth of cut increases. Changes in fiber orientation in the composite materials might change the surface roughness, and this is a study that will be investigated in the future. By using proper cutting conditions and machine tools, the surface quality in composite materials can be optimized.

Author Contributions: Conceptualization, G.M. and D.T.; methodology, G.M. and D.T.; software, P.K.; validation, P.K. and D.T.; formal analysis, P.K. and D.T.; investigation, A.K. and D.T.; resources, A.K.; data curation, P.K. and D.T.; writing-original draft preparation, D.T.; writing-review and editing, A.K., P.K., and D.T.; visualization, P.K.; supervision, G.M. and D.T.; project administration, G.M. and D.T.; All authors have read and agreed to the published version of the manuscript.

Funding: This research received no external funding.

Data Availability Statement: Data is contained within the article.

Acknowledgments: The authors would like to thank B\&T Composites for manufacturing the GFRP pipes using the filament winding process.

Conflicts of Interest: The authors declare no conflict of interest.

\section{References}

1. Perillo, G.; Vacher, R.; Grytten, F.; Sørbø, S.; Delhaye, V. Material characterisation and failure envelope evaluation of fil-ament wound GFRP and CFRP composite tubes. Polym. Test. 2014, 40, 54-62. [CrossRef]

2. Xu, X.; Zhang, W.; Ding, X. Modular design method for filament winding process equipment based on GGA and NSGA-II. Int. J. Adv. Manuf. Technol. 2017, 94, 2057-2076. [CrossRef]

3. Santulli, C. Mechanical and Impact Damage Analysis on Carbon/Natural Fibers Hybrid Composites: A Review. Materials 2019, 12, 517. [CrossRef] [PubMed]

4. Di, C.; Yu, J.; Wang, B.; Lau, K.-T.; Zhu, B.; Qiao, K. Study of Hybrid Nanoparticles Modified Epoxy Resin Used in Filament Winding Composite. Materials 2019, 12, 3853. [CrossRef] [PubMed]

5. Singh, M.; Singh, A.K. Magnetorheological finishing of grooved drum surface and its performance analysis in winding process. Int. J. Adv. Manuf. Technol. 2020, 106, 2921-2937. [CrossRef]

6. Cao, Y.; Cao, Z.; Zhao, Y.; Zuo, D.; Tay, T.E. Damage progression and failure of single-lap thin-ply laminated composite bolted joints under quasi-static loading. Int. J. Mech. Sci. 2020, 170, 105360. [CrossRef]

7. Caggiano, A. Machining of Fibre Reinforced Plastic Composite Materials. Materials 2018, 11, 442. [CrossRef]

8. Kechagias, J.; Petropoulos, G.; Iakovakis, V.; Maropoulos, S. An investigation of surface texture parameters during turning of a reinforced polymer composite using design of experiments and analysis. Int. J. Exp. Design Process Optim. 2009, 1, 164-177. [CrossRef]

9. Fountas, N.; Ntziantzias, I.; Kechagias, J.; Koutsomichalis, A.; Davim, J.P.; Vaxevanidis, N.M. Prediction of Cutting Forces during Turning PA66 GF-30 Glass Fiber Reinforced Polyamide by Soft Computing Techniques. Mater. Sci. Forum 2013, 766, 37-58. [CrossRef]

10. Dehghan, M.S.P.; Heidary, H. Parametric study on drilling of GFRP composite pipe produced by filament winding process in different backup condition. Compos. Struct. 2020, 234, 111661. [CrossRef]

11. Korlos, A.; Tzetzis, D.; Mansour, G.; Sagris, D.; David, C. The delamination effect of drilling and elec-tro-discharge machining on the tensile strength of woven composites as studied by X-ray Computed Tomography. Int. J. Mach. Machin. Mater. 2016, 18, 426-448.

12. Prasad, K.S.; Chaitanya, G. Experimental study on surface roughness and dimensional accuracy of hole machining process on GFRP composites using abrasive water jet technique. Mater. Today Proc. 2020, 23, 651-658. [CrossRef] 
13. El-Ghaoui, K.; Chatelain, J.-F.; Ouellet-Plamondon, C. Effect of Graphene on Machinability of Glass Fiber Reinforced Polymer (GFRP). J. Manuf. Mater. Process. 2019, 3, 78. [CrossRef]

14. Davim, J.P.; Mata, F. Optimisation of surface roughness on turning fibre-reinforced plastics (FRPs) with diamond cutting tools. Int. J. Adv. Manuf. Technol. 2004, 26, 319-323. [CrossRef]

15. Naveen, S.A.; Aravindan, S.; Noorul Haq, A. Influence of machining parameters on surface roughness of GFRP pipes. Adv. Product. Eng. Manag. 2009, 4, 47-58.

16. Gill, S.K.; Meenu; Satsangi, P.S. Multiple-response optimization of turning machining by the taguchi method and the utility concept using uni-directional glass fiber-reinforced plastic composite and carbide (k10) cutting tool. J. Mech. Sci. Technol. 2013, 27, 2829-2837. [CrossRef]

17. Singh, A.; Datta, S.; Mahapatra, S.S. Application of a Fuzzy Inference System for the Optimization of Material Removal Rate and Multiple Surface Roughness Characteristics in the Machining of GFRP Polyester Composites. Decis. Mak. Manuf. Serv. 2013, 7, 19-42. [CrossRef]

18. Hussain, S.A.; Kumar, P.; Krishna, G. Fuzzy rule-based optimization of multiple responses in turning of GFRP composites. Int. J. Adv. Sci. Technol. 2015, 74, 25-34. [CrossRef]

19. Raveendran, P.; Marimuthu, P. Multi-response optimization of turning parameters for machining glass fiber-reinforced plastic composite rod. Adv. Mech. Eng. 2015, 7, 1-10. [CrossRef]

20. Yardimeden, A. Investigation of optimum cutting parameters and tool radius in turning glass-fiber-reinforced composite material Sci. Eng. Compos. Mater. 2016, 23, 85-92. [CrossRef]

21. Mohan, M.; Balamurugan, A.; Ramakrishnan, M.; Gowrishankar, A.; Jagadeeshwar, V. Optimization of machining param-eters for GFRP composite in CNC lathe using Anova. Int. J. Innov. Eng. Technol. 2017, 8, 57-64.

22. Kharwar, P.K.; Verma, R.K. Grey embedded in Artificial Neural Network (ANN) based on hybrid optimization ap-proach in machining of GFRP epoxy composites. FME Trans. 2019, 47, 641-648. [CrossRef]

23. Equbal, A.; Shamim, M.; Badruddin, I.A.; Equbal, M.; Sood, A.K.; Nik Ghazali, N.N.; Khan, Z.A. Application of the combined ANN and GA for multi-response optimization of cutting parameters for the turning of Glass Fi-ber-Reinforced Polymer composites. Mathematics 2020, 8, 947. [CrossRef]

24. Subramanian, M.; Sakthivel, M.; Sudhakaran, R. Modeling and Analysis of Surface Roughness of AL7075-T6 in End Milling Process Using Response Surface Methodology. Arab. J. Sci. Eng. 2014, 39, 7299-7313. [CrossRef]

25. Efkolidis, N.; Hernandez, C.G.; Talon, J.L.H.; Kyratsis, P. Modelling and prediction of thrust force and torque in drilling operations of Al7075 using ANN and RSM methodologies. J. Mech. Eng. 2018, 64, 351-361.

26. Tzotzis, A.; García-Hernández, C.; Huertas-Talón, J.-L.; Kyratsis, P. 3D FE Modelling of Machining Forces during AISI 4140 Hard Turning. Stroj. Vestn. Ndash. J. Mech. Eng. 2020, 66, 467-478. [CrossRef]

27. Malakizadi, A.; Gruber, H.; Sadik, I.; Nyborg, L. An FEM-based approach for tool wear estimation in machining. Wear 2016, 368-369, 10-24. [CrossRef] 